Shandy as anticipating the novel and I made plain that the (postmodern) changes I observed 'came into common usage in Europe and the Unites States in the last three decades or so' (Hawthorn: p. 62). To negate (my) differentiating modernist fiction from the 1950s postmodernist 'shift' might make good criticism if not merely advanced as opinion.

On my text choices being idiosyncratic, I acknowledged this inevitability (p. vi) before providing choices of others as a balance, including David Goldberg. But this was ignored and readers left with assumptions of my eccentricity.

I did not identify psychoanalysis as a dominant force in the 1930s. I asserted its significance as an interest in Freudianism, in the 1920s, with 'think-tanks' involving John Rickman, Lionel Penrose, A. G. Tansley and John Bowlby, who qualified medically in the 1930s. This interest persisted into the 1950s, some medical superintendents being conversant with psychoanalysis whose emergent tensions, in psychiatry, I addressed in my chapter on Pat Barker's Regeneration. ${ }^{4}$

On Kafka's Metamorphosis being a short story: I quote acclaimed literary critic Harold Bloom: ${ }^{5}$ 'Considering the origins of this great short novel, The Metamorphosis' (p. 65).

In effect, your reviewer ignored most of my book, opting for points of little intellectual interest. As for my (perceived) disparaging remarks about psychiatry 'throughout the book', my critical take on psychiatrists Dr Yealland (Chapter 3) and Dr Weir-Mitchell (Chapter 5) stemmed from fiction. My 'disparaging comments' were exceptionally sporadic but their effect clearly outweighed the rest of my text.

It is false that I 'dismiss' Nietzsche, Socrates and Foucault. I critically quoted Foucault thus: 'Shall we try reason: to my mind nothing could be more futile' (p. 66). I attributed only to Socrates that he was Plato's mouthpiece and placed my take on Nietzsche within Hesse's Steppenwolf and Richard III.

In general, the review was ill-considered, selectively dismissive and factually inaccurate.

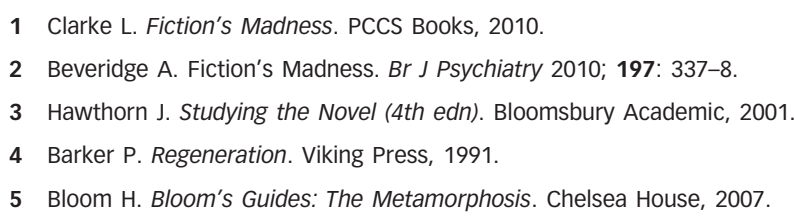

Liam Clarke, Reader in Mental Health, University of Brighton, 49 Darley Road, Eastbourne BN20 1EN, UK. Email: W.F.Clarke@brighton.ac.uk

doi: 10.1192/bjp.198.4.324a

Author's reply: I would like to make the following points. First, in referring to Laurence Sterne's Tristram Shandy, which is regarded by most commentators as a novel, I was challenging the author's contention that: 'From the eighteenth century through to the nineteenth, novels were realist by nature $[\ldots]$ from the 1950s, however, novels began to move in mysterious ways. Suddenly "Multivoiced" narratives, unreliable narrators, allegories, genre dodging, satire, and allusiveness [ . . . ] became the order of the day' (Clarke, ${ }^{1}$ pp. 11-12). Sterne's Tristram Shandy, written in the 18th century, and James Hoggs' The Private Memoirs and Confessions of a Justified Sinner, written in 1824, experiment with the genre and with the notion of the unreliable narrator. Indeed, Clarke himself (p. 17) cites Ford Madox Ford's 1915 novel The Good Soldier as representing a good example of an unreliable narrator.

Second, in his letter the author states that he did not identify psychoanalysis as a dominant force in the 1930s, but in his book he writes: 'Psychoanalysis was a major force in English psychiatry during the 1930s' (p. 150).

Third, as regards disparaging remarks about psychiatry, the quote about the smugness of male psychiatrists comes directly from the author, not from a novel. Elsewhere we find other critical remarks. Commenting on psychiatric training the author states: 'three years of preparation for membership of the Royal College of Psychiatrists [ . . . ] requires not a whit of training in interpersonal relations, little of self-reflection, or what it means to be human. Such diversions might inhibit the self-assuredness provided by a medical model of madness. Alternatively, of course, the hyped confidence may simply compensate for the psychiatrists' self-perceived fragility compared with the knowledge basis and status of other medical specialities' (p. 147).

Finally, with reference to a dismissive approach to major thinkers, the author discusses what he calls 'Socrates' infamous claim that no one can knowingly do wrong', and concludes: 'Perhaps Socrates got it wrong' (p. 156). He writes that 'Although Nietzsche's Superman (Ubermensch) was realised most horrifically, in our own time, by the Nazis, the impulse to stomp on others continues' (p. 136). He also observes: 'Foucault foolishly suggests abandoning rationality itself' (p. 186).

Allan Beveridge, Queen Margaret Hospital, Whitefield Road, Dunfermline KY12 OSU, UK. Email: allanbeveridge@nhs.net

doi: 10.1192/bjp.198.4.325

\section{Theories on the evolutionary persistence of psychosis}

We note that the Darwinian models of psychosis reviewed by Kelleher $e t a l^{1}$ in their editorial were all variants of the 'costly by-product' evolutionary model whereby an adaptive neurobiological system that enhances fitness in the vast majority of the population generates the risk of error in a small minority, resulting in psychosis (including schizophrenia). Burns ${ }^{2}$ identified the frontotemporal and frontoparietal cortical connections of the social brain, whereas $\mathrm{Crow}^{3}$ proposed that the dysregulation occurs in the language centres.

We wish to propose a different and entirely environmental Darwinian formulation for the non-affective psychoses based on an 'environmental mismatch' model. We have explained elsewhere $^{4}$ that, although we agree with Burns' proposal regarding locating the dysregulation and dysconnectivity within the social brain, we contend that the aetiology of the dysregulation relates to the effects of the novel post-Neolithic social environment. Although the susceptibility to non-affective psychosis, including schizophrenia, is likely to be ancient, the schizophrenic and the non-affective psychosis phenotype did not manifest itself until very recently in our species' history. In other words, the risk of these disorders lay dormant and did not become evident until the post-Neolithic period.

Hence, we have proposed a reformulation of the social brain theory of schizophrenia and contend that schizophrenia (and the non-affective psychoses) are novel human phenomena that arose following the establishment of large permanent human settlements that accompanied the advent of agriculture and the abandonment of the hunter-gatherer way of life. We have contended that the blurring of the demarcation between in-group and out-group membership and living in close proximity to strangers is a stressor that can lead to perturbation in the development of the social brain in vulnerable individuals, resulting in the syndrome of schizophrenia. Hence, according to our formulation, schizophrenia is the result of a mismatch between the post-Neolithic human social environment and the 